\title{
Simulation of a high frequency on/off valve actuated by a piezo-ring stack for digital hydraulics
}

\author{
Paolo Tamburrano ${ }^{1 *}$, Pietro De Palma ${ }^{1}$, Andrew R. Plummer ${ }^{2}$, Elia Distaso ${ }^{1}$, Francesco \\ Sciatti $^{1}$ and Riccardo Amirante ${ }^{1}$ \\ ${ }^{1}$ Department of Mechanics, Mathematics and Management (DMMM), Polytechnic University of Bari, \\ Bari, Italy. \\ ${ }^{2}$ Centre for Power Transmission and Motion control (PTMC), University of Bath, Bath, UK.
}

\begin{abstract}
Despite being widely used in several applications, commercially available spool valves, both servovalves and proportional valves, are inefficient components because they cause high power consumption due to the large pressure drops across the metering orifices. A recent research field aims at substituting spool valves with on/off valves having high switching frequency (changing state between open and closed in a few milliseconds or less) and producing low pressure drops, in order to make the so-called digital hydraulics possible. In spite of the advantages that it could provide, digital hydraulics does not have significative industrial applications yet, because of the difficulty in manufacturing such high frequency on/off valves. Hence, this paper performs a feasibility study of an on/off poppet-type valve actuated directly by a commercially available ring stack, which is a multilayer piezo-actuator capable of generating very high actuation forces needed for this application. Modulation of the average flow can be achieved by changing the duty cycle of the pulse width modulation (PWM) signal driving the piezostack. An inertance tube could also be used to smooth flow pulsation. The simulations obtained using a detailed Simulink model show that high switching frequency and very effective flow modulation can be obtained with this valve architecture along with low pressure drops and high flow rates, thus making it potentially suitable for digital hydraulics. The disadvantages of this single stage architecture are the large dimensions of the piezo stacks, and the high current generated because of both the high capacitance of the piezo stack and the high frequency switching. However, large-scale production of these components could help to reduce the costs, and the simulations show that limiting the maximum current to $10 \mathrm{~A}$ still provides good regulation.
\end{abstract}

Keywords: ring stack, digital hydraulics, ON/OFF valves, PWM

${ }^{*}$ Corresponding author: paolo.tamburrano@poliba.it 


\section{Introduction}

Proportional and servovalves are employed in several industrial and aeronautical applications. The position and velocity of a cylinder is accurately controlled by acting on the flow rate delivered to the cylinder, which in turn is controlled by acting on the spool position of the control valve, which can have infinite values depending on the control signal [1, 2]. Proportional valves are mainly used in industrial applications. Instead, in aircraft, flight control surfaces (e.g. elevators, ailerons, rudders, flaps, etc.) are usually actuated using a servovalve, because of the faster response and lower weight than a proportional valve. A proportional valve is usually a single stage configuration in which the spool is directly moved by solenoids; whereas a servovalve employed in aircraft is usually a two-stage configuration, in which the spool is actuated by a pilot stage providing hydraulic amplification. Direct-drive (single stage) servovalves are also manufactured, in which a large linear force motor (LFM) is used to directly move the spool, thus being suitable for industrial applications. The main difference between a proportional valve and a servovalve (two stage or single stage) is that the latter is provided with a bushing sleeve, which allows better manufacturing tolerances, lower overlaps, and faster response [1,2].

Regardless of this difference, both proportional and servovalves employ a sliding spool, which causes high power consumption, due to two main reasons: 1) internal leakage occurs in the main stage due both to geometrical tolerances necessary to make the spool move and to geometrical imperfections [3, 4];2) the pressure drop suffered by the pressurised oil from the pump to the cylinder and viceversa is always very high because the oil passes through the small passages of the main stage [1]. In addition, a third cause of power consumption occurs for two stage servovalves: 3 ) even when the valve is at rest, the pilot stage continuously requires a quiescent flow to operate, which is taken from the pump and is then discharged into the tank [1].

Research is quite active to study losses 1) and 3), namely, the internal leakage in the main stage and the quiescent flow in the pilot stage (to be referred to as the internal leakage in the pilot stage). Concerning the former, current research studies have investigated the effects of geometrical imperfections, due to wear and manufacturing processes, showing that such imperfections have a huge effect on the overall leakage [3-6]. Concerning the latter, novel configurations for the pilot stage have been proposed and are currently being studied taking advantage of piezo-electric actuators, showing that the internal leakage of the pilot stage can be reduced using such configurations [7-9].

The second cause of power consumption, namely, the large pressure drops experienced by the oil when flowing through the main stage, is due to the fact that the main stage is a spool valve in which the flow rate is changed by acting on its opening degree. Fig. 1 shows a typical circuit employing a 4/3 symmetrical servovalve coupled with a double ended cylinder. Denoting the flow rate across the valve by $Q_{v}$ and the spool position by $x$, the following relation exists $[1,10]$ :

$$
Q_{v}=C_{D} x w \sqrt{\frac{2 \Delta p_{A_{r}}}{\rho}},
$$

where the term $x w$ represents the restriction area $A_{r}$ across the metering sections of the valve ( $w$ being the width of the slots), $C_{D}$ is the discharge coefficient (usually comprised between 0.6 and 0.7 for turbulent flows [1]), $\rho$ is the oil density and $\Delta p_{A_{r}}$ is the pressure drop across 
the metering section $A_{r}\left(\Delta p_{A_{r}}=\Delta p_{P-B}=\Delta p_{A-T}\right.$ because the valve is assumed to be symmetrical).

In order to have fast response speed and good regulation accuracy, the diameter of the spool is usually comprised between $D=5 \mathrm{~mm}$ and $D=8 \mathrm{~mm}$, whilst the maximum spool position is of the order of $1 \mathrm{~mm}$. The width of the slots can be as high as $2 / 3$ of the spool perimeter. With these values, the restriction area $A_{r}=x w$ is very low, causing a large pressure drop according to equation (1). This pressure drop across the modulating valve causes power dissipation $P_{d}$, which can be estimated as follows:

$$
P_{d}=2 \frac{Q_{v} \Delta p_{A_{r}}}{\eta_{p}},
$$

where $\eta_{p}$ is the pump efficiency and the factor 2 is due to the fact that two metering sections are open simultaneously in a $4 / 3$ valve. Considering possible values for a medium-size valve, namely, $C_{D}=0.7, D=8 \mathrm{~mm}, x=1 \mathrm{~mm}, w=2 / 3 \pi D, \rho=850 \mathrm{~kg} / \mathrm{m}^{3}, Q=601 / \mathrm{min}$, and $\eta_{p}=0.85$, equations (1) and (2) lead to a predicted pressure drop equal to $\Delta p_{A_{r}} \approx 30$ bar and a power dissipation equal to $P_{d} \approx 7 \mathrm{~kW}$. This loss is further increased because a modulating valve always needs an upstream pressure relief valve (as shown in Fig.1), which must be always open in order to set a constant pressure upstream of the modulating valve; therefore, a part of the flow $Q_{L}$ is discharged through the pressure relief valve, causing additional power consumption.

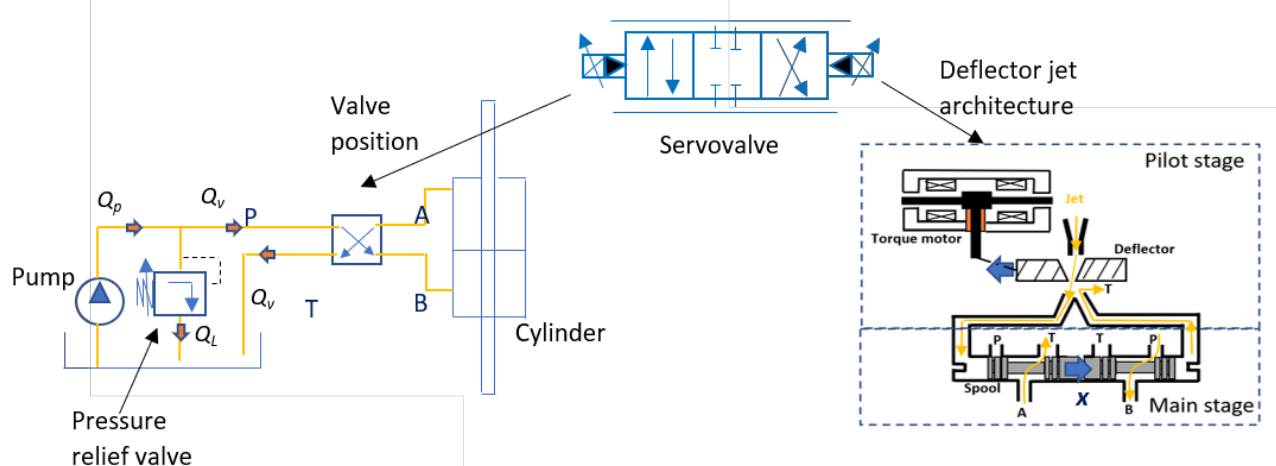

Fig. 1. Typical hydraulic circuit employing a symmetric servovalve coupled with a double ended cylinder [8].

This simple calculation explains the reason why these power conversion systems are inefficient in terms of power consumption. A recent research field aims at substituting servovalves and proportional valves with digital hydraulics, in an attempt to reduce such high-power dissipations [11-13]. A digital hydraulic circuit can be either that shown in Fig. 2 (a) or that shown in Fig. 2(b) [11]. The former (Fig. 2(a)) is called a digital flow control unit. It can realize the accurate flow control through encoding control of multiple switching valves connected in parallel. The switching valves are two-way two-position valves which are either fully open or fully closed. Each valve is normally closed when in the rest position and passing flow when actuated. If there are $\mathrm{N}$ switching valves in the circuit, there will be $2^{\mathrm{N}}$ possible combinations, therefore flow modulation is obtained by deactivating (status 0 ) and activating (status 1 ) the valves. The valves would typically have flow rates of 1, 2, 4, 8, 
16, etc. L/min according to the binary system [14]. These valves, being ON/OFF, do not need a spool modulating flow and, therefore, can have the same architecture as that of poppet valves. These valves have the potential to generate lower pressure drops than proportional valves because the flow area can be designed large.

The second circuit (Fig.2(b)) is called pulse modulation switching digital circuit. The valves employed in this circuit are again ON/OFF and are the same as those described in the previous case but are larger. In this case, a pulse signal (from 0 to 1 ) is delivered to the digital valve and flow modulation is obtained by changing the frequency of the pulse signal: the higher the frequency, the higher the average flow rate obtained. The intermittence of flow rate obtained with this system can be compensated by using accumulators and inertance tubes $[12,13]$. Also in this case, the use of ON/OFF valve has the potential to drastically reduce the pressure losses. The second circuit (Fig.2(b)) should be preferred over the first one (Fig.2(a)), because a lower number of valves is needed in the second one.

In addition to reducing the pressure drops and hence the power losses, the digital hydraulic technology directly adopts digital signals to control valves without $\mathrm{D} / \mathrm{A}$ conversion, which simplifies the control mode and removes the noise sensitivity typical of servovalves [11].

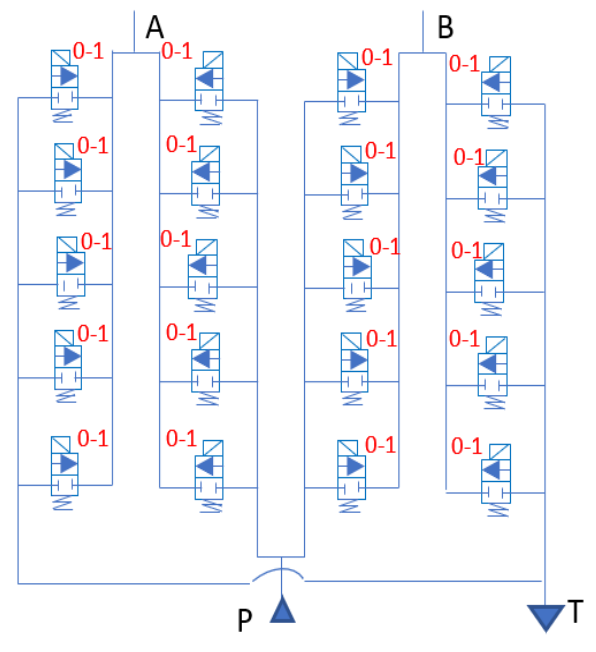

(a)

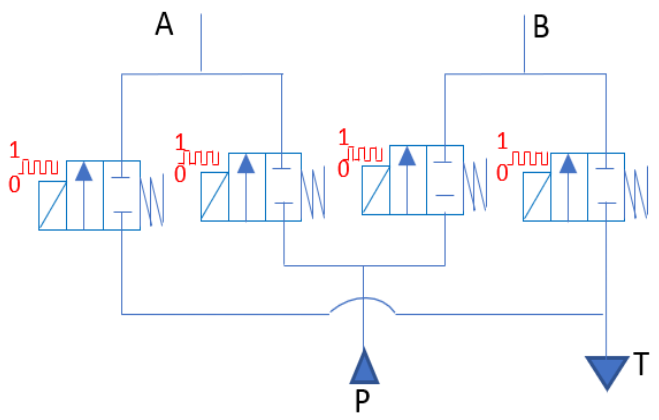

(b)

Fig. 2. Two schemes of digital hydraulics: digital flow control unit (a) and pulse modulation switching digital circuit (b).

In spite of the advantages that it can provide, digital hydraulics does not have practical applications yet, apart from very small circuits, because of the difficulty in manufacturing the ON/OFF valves required for this purpose. Indeed, these valves must be very fast, of the order of a few milliseconds, to change state between open and closed. In the literature, there are some examples of novel valve architectures designed to achieve very fast response, but these designs are limited to low flow applications and are not suitable for high flow circuits [11].

In this scenario, the aim of this study is to study a novel ON/OFF valve architecture which can be manufactured and used in the digital hydraulic circuit shown in Fig. 2(b), towards the 
implementation of digital hydraulics in aircraft and in industrial applications in place of proportional valves and servovalves. The idea here presented consists in using a piezoelectric actuator called ring stack, which moves a piston in a poppet valve. The use of piezoelectric actuators, which has already been proved to be feasible for the direct actuation of spool valves (see, e.g., [15-19]), can be the right solution for the development of such high switching ON/OFF valves.

In the following section, the architecture of the proposed valve is described, along with the equations implemented in a Simulink code to simulate this valve. The results of the simulations are then presented and discussed. The results allow advantages and disadvantages to be deduced and discussed in the conclusions.

\section{Methodology}

A poppet-type valve directly actuated by a piezo-electric actuator is simulated in this paper to assess whether it could be employed in the circuit shown in Fig. 2 (b). The valve must meet the following targets:

$\checkmark \quad$ it must switch between open and closed in a very short time. A large unit should switch in less than $5 \mathrm{~ms}$;

$\checkmark$ it must generate low pressure drops even for high flow rates. A real target is to achieve a maximum pressure drop of 10 bar at $60 \mathrm{~L} / \mathrm{min}$ for large units;

$\checkmark \quad$ it must ensure robustness, since it must switch several times a day and thus it is important to make sure that it is very robust to meet life cycle requirements.

The architecture here explored is shown in Fig. 3. The proposed architecture is based on the use of a multilayer piezo ring stack actuator produced by the manufacturer Noliac [20]. It is composed of several ring layers which are stacked to fit the needed height or stroke. Depending on the number of layers, different combinations of maximum free stroke and blocking force can be obtained. The maximum free stroke is the displacement ideally achievable corresponding to a null actuation force; instead, the maximum blocking force is the maximum actuation force achievable when the stack is blocked. The piezo actuator with the maximum height $(200 \mathrm{~mm})$, maximum free stroke $\left(x_{\text {free }}=326.7 \mu \mathrm{m}\right)$ and maximum blocking force $\left(F_{b, \max }=8450 \mathrm{~N}\right)$ is considered in this analysis, namely model NAC2125-HXX [20]. This actuator has stiffness $k_{p}=26000000 \mathrm{~N} / \mathrm{m}^{2}$.

As shown in Fig.3, the proposed valve is a two-way two-position (2/2) poppet type valve, in which the ring stack (1) directly moves the valve piston (2), which is inserted through the hole of the stack (3). To operate correctly, the piezo stack needs a pre-compression $\delta_{0}$. The values for the optimum preload ranges from 20 to 50 percent of the maximum blocking force [21]. This is achieved by a spring (4), which is also tasked with keeping the piston in contact with the piezo-stack. The piston must be shaped as shown in Fig. 3 to allow pressure compensation. When an amplified voltage is applied to the piezo-electric actuator, the piston is moved from its seat and flow can pass from port $\mathrm{P}$ to port $\mathrm{A}$. This valve has the potential to meet the targets defined previously, taking advantage of the fast response of both the piezoelectric actuator and the simplicity of its architecture. 


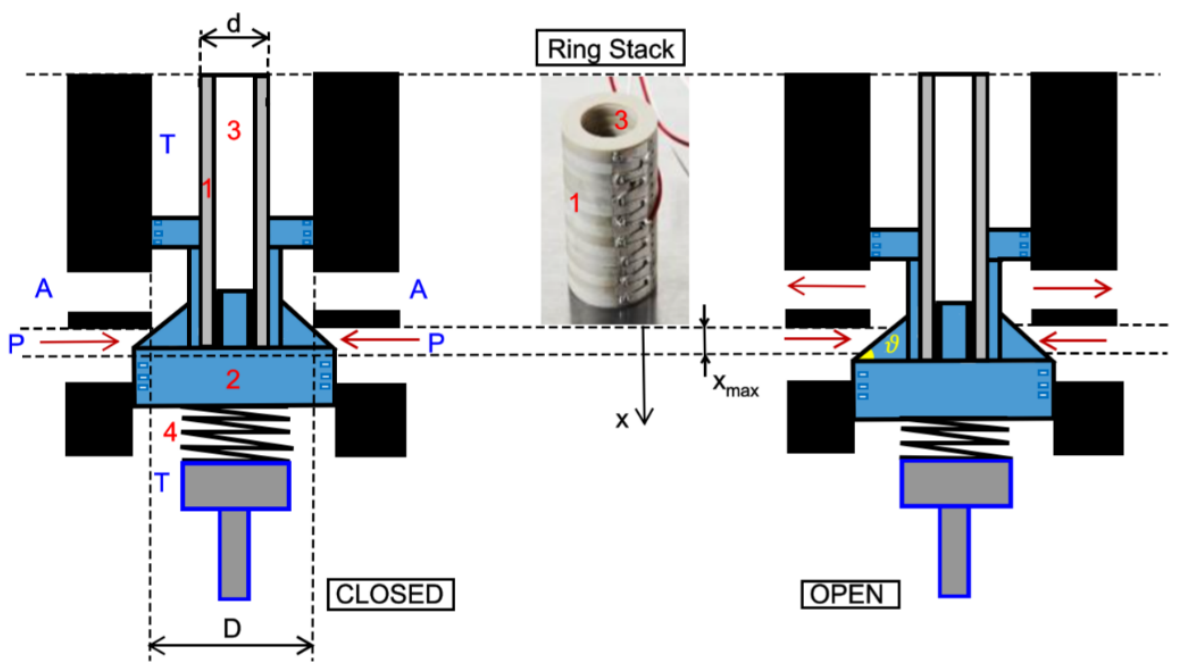

Fig. 3. Proposed ON/OFF valve architecture to be investigated: closed position (left), open position (right)

This valve is studied using well-established equations, implemented in a Simulink model. To predict the performance, $p_{p}$ and $p_{A}$ are assumed to be constant, with $p_{A}$ equal to the atmospheric pressure. When the valve opens, the equilibrium of the forces acting on the piston can be written as follows [10]:

$$
F_{b}-k_{p} x-k_{s}\left(x+\delta_{0}\right)-F_{f}-C \dot{x}-m \ddot{x}=0,
$$

where $F_{b}$ is the blocking force, $k_{p}$ is the stiffness of the piezostack, $x$ is the displacement of the valve piston; $k_{s}$ is the stiffness of the additional spring, which is used to provide the piezo-stack with a pre-compression $\delta_{0}$; the flow force is denoted by $F_{f} ; C$ and $m$ are respectively the damping factor (accounting for fluid viscosity) and the mass of the moving parts.

The flow force $F_{f}$ and the flow rate $Q$ are calculated as follows [9, 10, 22]:

$$
\begin{gathered}
F_{f}=\rho \frac{Q^{2}}{A_{r}} \cos \theta, \\
Q=C_{D} A_{r} \sqrt{\frac{2\left(p_{P}-p_{A}\right)}{\rho}},
\end{gathered}
$$

where $C_{D}$ is the discharge coefficient and $\theta$ is the piston angle (see Fig.3) equal to the flow angle. The restriction area $A_{r}$ is calculated as follows:

$$
A_{r}=\pi D x \sin \theta
$$

where $D$ is the effective diameter of the piston. The piston stroke is limited by two stops which restrict its motion between an upper and a lower bound. Each stop is represented by a spring coupled with a damper. A force $F_{\text {stop }}$ acts on the ring bender when the maximum displacement $\left(x=x_{\max }\right)$ and the minimum displacement $(x=0)$ are reached [22]: 


$$
\begin{gathered}
F_{\text {stop }}=K_{\text {stop }}\left(x_{\text {max }}-x\right)+C_{\text {stop }} \frac{d}{d t}\left(x_{\text {max }}-x\right) \\
\text { for } x \geq x_{\text {max }}, \\
F_{\text {stop }}=K_{\text {stop }}\left(x_{\text {min }}-x\right)+C_{\text {stop }} \frac{d}{d t}\left(x_{\text {min }}-x\right) \\
\text { for } x \leq 0,
\end{gathered}
$$

where $K_{\text {stop }}$ and $C_{\text {stop }}$ are the stiffness and damping of the mechanical stops.

To evaluate the damping factor of the moving parts, which is due to the frictional forces acting on it, the following relation can be used [23]:

$$
C=\frac{\mu \pi D_{p} l_{p}}{c \sqrt{\left(1-\left(\frac{\varepsilon}{c}\right)^{2}\right.}},
$$

where $\mu$ is the dynamic viscosity of the oil, $D_{p}$ and $l_{p}$ are respectively the diameter and length of the parts in contact with the case; $c$ is the radial clearance and $\varepsilon$ is the radial eccentricity.

The volume of oil comprised between the inlet $(\mathrm{P})$ and the outlet $(\mathrm{A})$ is simulated using a block named "Constant Volume Hydraulic Chamber". With this block, a fixed-volume chamber with rigid walls is simulated and the fluid compressibility is taken into account. The following equations are applied [22]:

$$
\begin{gathered}
V_{\text {cham }}=V_{o}+\frac{V_{0} p}{E}, \\
q_{c}=\frac{d V_{\text {cham }}}{d t}=\frac{V_{o}}{E} \frac{d p}{d t},
\end{gathered}
$$

where $V_{0}$ is the geometrical volume of the chamber (equal to the product of an internal diameter $D_{0}$ and an overall internal length $L_{0}$ ), $V_{\text {cham }}$ is the oil volume in the chamber at the pressure $p$, with $q_{c}$ denoting the flow rate through the chamber. The actual bulk modulus $E$ is calculated as follows $[10,22]$ :

$$
E=E_{o} \frac{1+\varepsilon\left(\frac{p_{a}}{p}\right)^{1 / \gamma}}{1+\varepsilon \frac{p_{a}^{1 / \gamma}}{\gamma p^{(\gamma+1) / \gamma}} E_{o}},
$$

where $E_{0}$ is the pure liquid bulk modulus, $p_{a}$ is the atmospheric pressure, $\gamma$ is the gas-specific heat ratio $(\gamma=1.4)$ and $\varepsilon$ is the relative gas content at atmospheric pressure.

The amplifier is simulated by using a second order transfer function [24]:

$$
V_{a m p}=\frac{K_{a} \omega_{n}^{2}}{s^{2}+2 \xi \omega_{n} s+\omega_{n}^{2}} V_{c}
$$

where $V_{c}$ is the control voltage supplied to the amplifier (from $0 \mathrm{~V}$ to $5 \mathrm{~V}$ ), $K_{a}$ is the gain of the amplifier $\left(K_{a}=40\right), \omega_{n}$ is the natural frequency of the amplifier, and $\xi$ is the damping factor of the amplifier. Amplifiers for piezoelectric actuators usually generate a low noise 
voltage output, therefore noise is not simulated in this analysis [25]. The current is calculated using the following equation:

$$
I=\frac{d V_{a m p}}{d t} C_{a p}
$$

where $C_{a p}$ is the capacitance of the piezo-stack. In the model, it is also possible to limit the maximum current by setting a maximum value for the current $I_{\max }$.

The hysteresis of the ring stack is not modelled in this analysis because there are not experimental data provided by the manufacturer concerning the ring stack employed.

The Simulink solver (Ode 14x) computes the dynamic system's states at successive time steps $(0.01 \mathrm{~ms})$ over a specified time span $(25 \mathrm{~ms})$, using information provided by the model [22].

\section{Results}

The simulations were performed using the following data, as shown in Table 1. The parameters of the ring stack (model NAC2125-HXX [20]) are: $x_{\text {free }}=0.325 \mathrm{~mm}, F_{b, \max }=8450$ $\mathrm{N}, k_{p}=2610^{6} \mathrm{~N} / \mathrm{m}^{2} ; C_{a p}=79300 \mathrm{nF}$. The outer diameter of the ring stack is $d=20 \mathrm{~mm}$. The effective diameter of the piston was taken equal to $D=60 \mathrm{~mm}$; the piston angle was taken equal to $\theta=45 \mathrm{deg}$. The discharge coefficient was set to $C_{D}=0.7$, under the assumption of turbulent flow (reliable assumption for most of the piston travel given the operating conditions considered in the simulations) [10].

Table 1. Parameters employed in the simulations.

\begin{tabular}{|c|c|c|c|}
\hline Parameter & Symbol & Unit & Value \\
\hline Maximum free stroke & $x_{\text {free }}$ & $\mathrm{mm}$ & 0.325 \\
\hline Max. blocking force & $F_{b, \max }$ & $\mathrm{N}$ & 8450 \\
\hline Stiffness of the piezo-actuator & $k_{p}$ & $\mathrm{~N} / \mathrm{m}$ & $2610^{6}$ \\
\hline Capacitance & Cap & $\mathrm{nF}$ & 79300 \\
\hline Effective piston diameter & $D$ & $\mathrm{~mm}$ & 60 \\
\hline Piston angle & $\theta$ & $\mathrm{deg}$ & 45 \\
\hline Discharge coefficient & $C_{D}$ & - & 0.7 \\
\hline Inlet pressure & $p_{P}$ & $\mathrm{bar}$ & 11 \\
\hline Outlet pressure & $p_{A}$ & $\mathrm{bar}$ & 1 \\
\hline Mass of the moving parts & $m$ & $\mathrm{~g}$ & 100 \\
\hline Stiffness of the additional spring & $k_{s}$ & $\mathrm{~N} / \mathrm{m}$ & 190000 \\
\hline Pre-compression & $\delta_{0}$ & $\mathrm{~mm}$ & 8.90 \\
\hline Spring stiffness (mech. stop) & $K_{\text {stop }}$ & $\mathrm{N} / \mathrm{m}$ & $10^{8}$ \\
\hline Damping (mech. stop) & $C_{\text {stop }}$ & $\mathrm{Ns} / \mathrm{m}$ & 5000 \\
\hline Volume chamber & $V_{0}$ & $\mathrm{~m}^{3}$ & $210^{-4}$ \\
\hline Oil density & $\rho$ & $\mathrm{kg} / \mathrm{m}^{3}$ & 851 \\
\hline Damping coefficient & $C$ & $\mathrm{Ns} / \mathrm{m}$ & 60 \\
\hline Natural frequency of the amplifier & $\omega_{n}$ & $\mathrm{rad} / \mathrm{s}$ & 10000 \\
\hline Damping factor of the amplifier & $\xi$ & - & 1.5 \\
\hline
\end{tabular}


The inlet pressure was set to $p_{P}=11$ bar and $p_{A}=1$ bar, in order to have an overall pressure drop of 10 bar (the same results will be obtained for a different inlet pressure but with the same pressure drop). This was done since, as explained earlier, the objective is to design a valve which can produce high flow rate with low pressure drop. These parameters allow a flow rate of about $70 \mathrm{l} / \mathrm{min}$ to be achieved at the maximum opening. The mass of the moving parts was assumed $m=100 \mathrm{~g}$. The stiffness of the additional spring was assumed equal to $k_{s}=$ $190000 \mathrm{~N} / \mathrm{m}$ with a pre-compression $\delta_{0}=8.90 \mathrm{~mm}$, in order to obtain a preload equal to $20 \%$ of the maximum blocking force [21]. The maximum displacement (mechanical stop) is assumed equal to the maximum free stroke of the ring stack, $x_{\max }=0.325 \mathrm{~mm}$. The spring stiffness and damping of the mechanical stops were taken equal to $K_{\text {stop }}=10^{8} \mathrm{~N} / \mathrm{m}$ and $C_{\text {stop }}=5000 \mathrm{Ns} / \mathrm{m}$, respectively. The chamber accounting for fluid compressibility, given the dimensions of the piston, was assumed to have $D_{0}=D=60 \mathrm{~mm}$ and $L_{0}=D=60 \mathrm{~mm}$, thus obtaining $V_{0}=210^{-4} \mathrm{~m}^{3}$. The oil was assumed to be ISO VG 32 at $50{ }^{\circ} \mathrm{C}$, characterized by $\rho=851 \mathrm{~kg} / \mathrm{m}^{3}$ and $\mu=0.0187 \mathrm{~kg} /(\mathrm{m} \mathrm{s})$. The damping factor of the piston was calculated using equation (9): assuming $l_{p}=50 \mathrm{~mm}, D_{p}=60 \mathrm{~mm}$ and an eccentricity equal to zero, the calculated damping factor was $C=60 \mathrm{Ns} / \mathrm{m}$. Concerning the amplifier, the natural frequency was assumed equal to $\omega_{n}=10000 \mathrm{rad} / \mathrm{s}$ (with damping factor $\xi=1.5$ ), in order to simulate a high-performance amplifier. With the proposed setting, an input pulse voltage $V_{c}$ from 0 to $5 \mathrm{~V}$ with a frequency of $200 \mathrm{~Hz}$ (overall period $\tau=5 \mathrm{~ms}$ ) was simulated by changing the duration of the pulse. Keeping the period constant and changing the pulse duration $\Delta t_{o n}$, it means that the duty cycle of the input signal was changed $\left(\% D C=\Delta t_{o n} / \tau \%\right)$. The proposed setting is consistent with the requirement exposed in section 2 , since the valve must switch between on and off in a very short time, and the average flow rate must be regulated by acting on the pulse width. The use of a $200 \mathrm{~Hz}$ input frequency should not be an issue in terms of lifetime of the piezo-stack. Indeed, tests have shown that multilayer piezo-stacks can perform billions of cycles without a significative loss of performance even for higher frequencies than $200 \mathrm{~Hz}$ if operated under suitable conditions [26]. The main factor affecting the performance and lifetime of a piezo stack is the applied voltage, which must be limited to the values specified by the manufacturer. Indeed, some studies have demonstrated that a very high voltage can accelerate the fatigue failure of piezo stacks [27].

Figures 4, 5 and 6 respectively show the numerical predictions obtained for $\% D C=40 \%$, $\% D C=70 \%$ and $\% D C=100 \%$ of the input voltage pulse $\left(V_{c}\right)$. No limitation to the maximum current was set in the code. The amplified voltage $\left(V_{a m p}\right)$, the flow rate $(Q)$, the current $(I)$, and the piston position $(x)$ are plotted along with the input voltage $\left(V_{c}\right)$. The input voltage $\left(V_{c}\right)$, multiplied by 20 for clarity of representation, is plotted as a red line. The amplifier transforms this input pulse into a high voltage pulse $\left(V_{\text {amp }}\right)$, plotted as a blue line. Because of the time delay of the amplifier, about $1.5 \mathrm{~ms}$ are needed to obtain $V_{\text {amp }}=200 \mathrm{~V}$. The amplified voltage makes the piston move, with the piston reaching a maximum position and then oscillating around this position (see the green line representing the piston position). The maximum free stroke $(0.325 \mathrm{~mm})$ is not reached, because of the resistance forces (force of the additional spring and flow force). According to the trend of the piston position, a similar trend of the flow rate is obtained (orange line). Flow is obtained during the ON phase, while no flow is obtained during the OFF phase. Accordingly, a mean flow rate (see dotted line) is calculated by the program along the entire simulated test.

As shown in the figures, a similar maximum opening is reached in all the three cases, but the different duty cycle causes different values of the average flow, which increases with the duty cycle $(26 \mathrm{l} / \mathrm{min}$ for $\% D C=40 \%, 46 \mathrm{l} / \mathrm{min}$ for $\% D C=70 \%, 70 \mathrm{l} / \mathrm{min}$ for $\% D C=100 \%)$. In the case of $\% D C=100 \%$, the input pulse signal is transformed into a step signal, and the OFF phase does not exist. In all the three cases, the regulation is very effective, given the fast response of the simulated amplifier. Large oscillations of the flow rate are noticed. In practice, there could be less oscillation and the effective damping could be higher; one 
contribution could be hysteresis which would give some dissipation and generate increased damping. In any case, the oscillations of the flow rate can be smoothed by using an accumulator and an inertance tube $[12,13]$.

A very large value of the peak current (black line) is predicted by the simulations, which means high power consumption and related heating issues. However, this peak value occurs only for a short time interval; therefore, the average current is much lower.

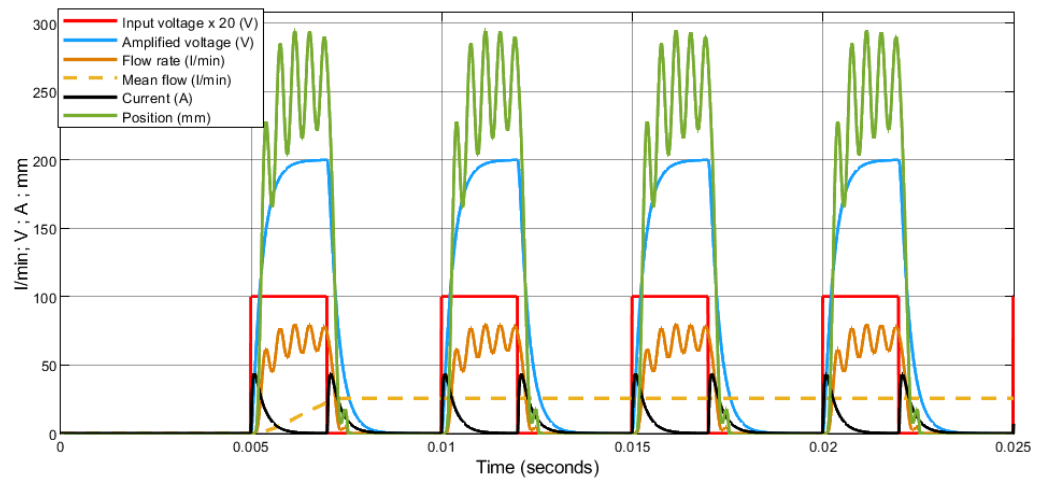

Fig. 4. Numerical predictions of amplified voltage $\left(V_{a m p}\right)$, flow rate $(Q)$, current $(\mathrm{I})$, and piston position (x) for $V_{c}$ changing from 0 to $5 \mathrm{~V}$ with a frequency of $200 \mathrm{~Hz}$ and $\% D C=40 \%$ (no limit for the maximum current).

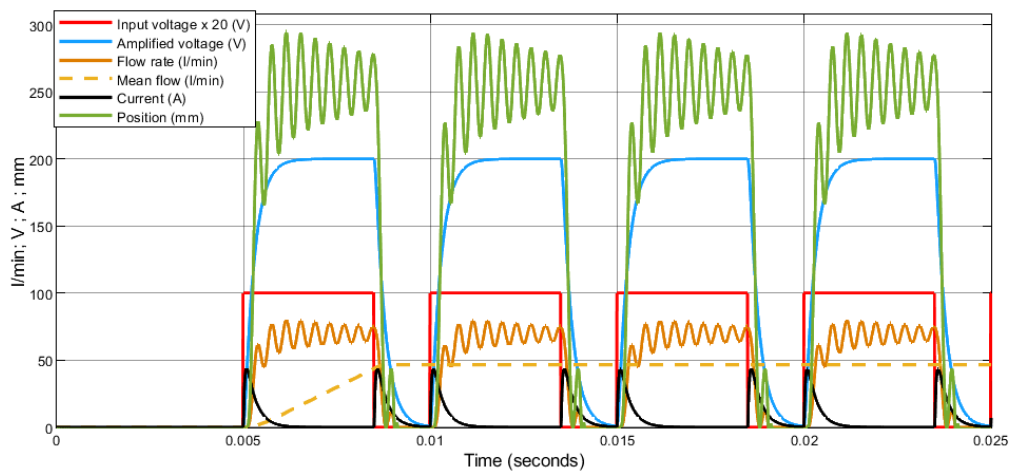

Fig. 5. Numerical predictions of amplified voltage $\left(V_{\text {amp }}\right)$, flow rate $(Q)$, current $(I)$, and piston position (x) for $V_{c}$ changing from 0 to $5 \mathrm{~V}$ with a frequency of $200 \mathrm{~Hz}$ and $\% D C=70 \%$ (no limit for the maximum current). 


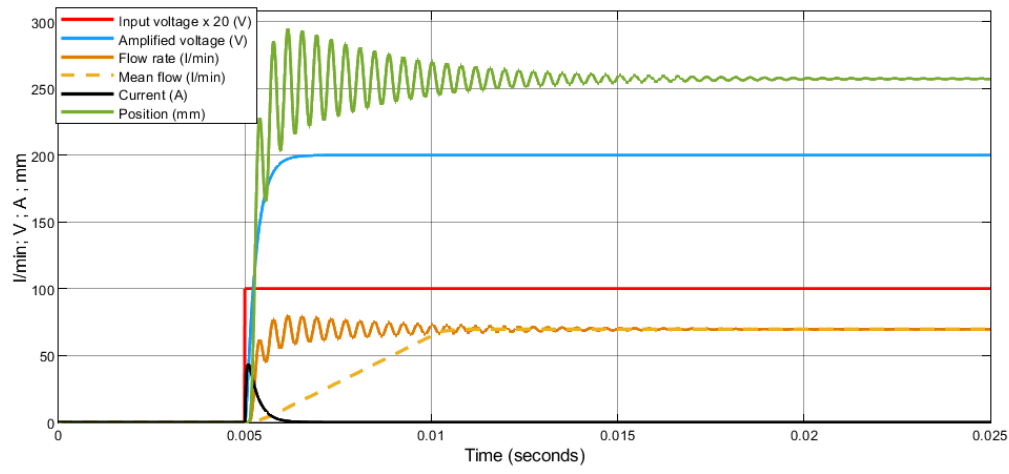

Fig. 6. Numerical predictions of amplified voltage $\left(V_{\text {amp }}\right)$, flow rate $(Q)$, current $(I)$, and piston position (x) for $V_{c}$ changing from 0 to $5 \mathrm{~V}$ with a frequency of $200 \mathrm{~Hz}$ and $\% D C=100 \%$ (no limit for the maximum current).

To reduce the peak current, a current limit can be set in the program. In this regard, Figures 7, 8 and 9 again show the numerical predictions of the amplified voltage $\left(V_{\text {amp }}\right)$, flow rate $(Q)$, current $(I)$, and piston position $(x)$ for $\% D C=40 \%, \% D C=70 \%$ and $\% \mathrm{DC}=100 \%$, but with a maximum current $I_{\max }=10$ A.

Having limited the maximum current, the time delay of the amplifier is increased to about $2 \mathrm{~ms}$. The shape of the curves has changed accordingly. Although the response time of the amplified voltage is worsened because of the current limit, these graphs show that the flow modulation is still effective and similar values of the mean flow are obtained compared to the previous case with no current limit.

However, a further reduction of the maximum current leads to poor response. Indeed, Fig. 10 shows the numerical predictions of the amplified voltage $\left(V_{\text {amp }}\right)$, flow rate $(Q)$, current $(I)$, and piston position $(x)$ for $\% \mathrm{DC}=70 \%$ and maximum current $I_{\max }=5 \mathrm{~A}$. Because the response time of the amplifier is now very close to one half of the period (5 ms), due to the current limit, it is shown that the valve cannot be fully closed during the OFF phase (the piston does not come back to $x=0$ ), thus leading to poor regulation.

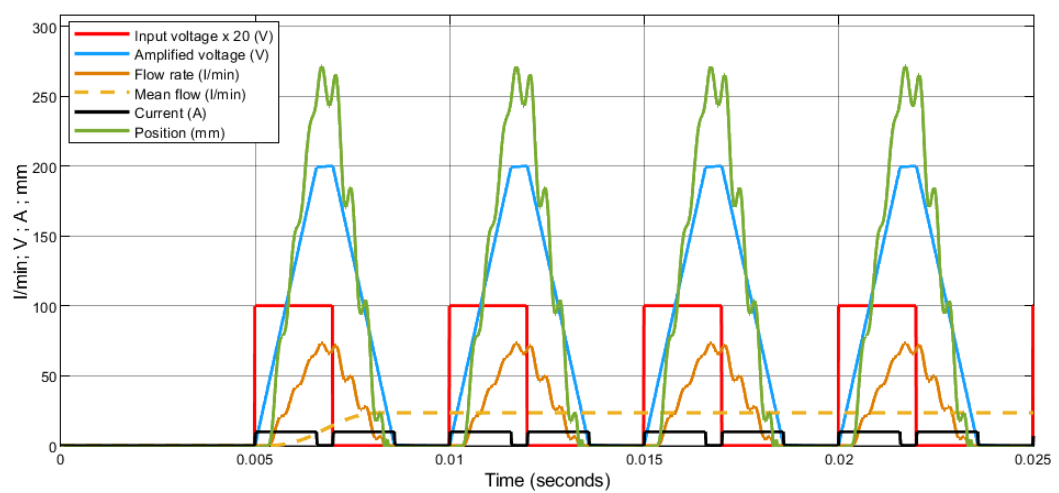

Fig. 7. Numerical predictions of amplified voltage $\left(V_{\text {amp }}\right)$, flow rate $(Q)$, current $(I)$, and piston position $(x)$ for $V_{c}$ changing from 0 to $5 \mathrm{~V}$ with a frequency of $200 \mathrm{~Hz}$ and $\% D C=40 \%\left(I_{\max }=10 \mathrm{~A}\right)$. 


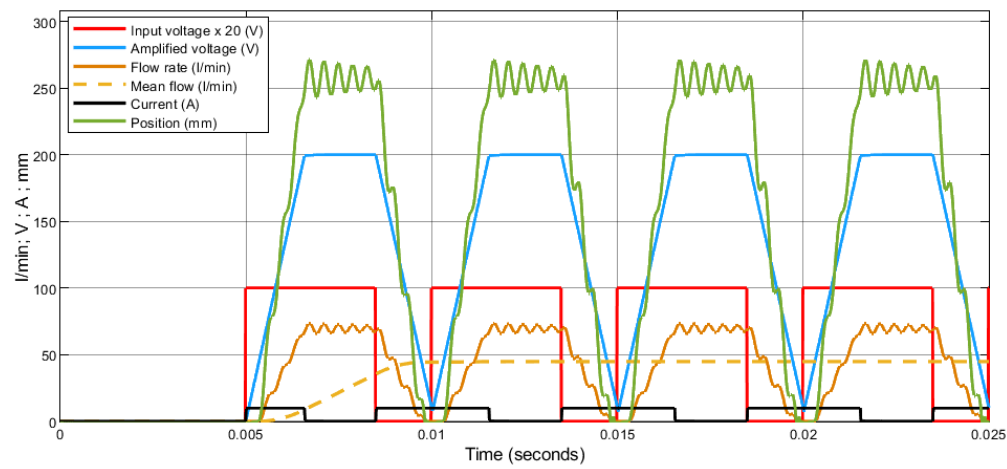

Fig. 8. Numerical predictions of amplified voltage $\left(V_{a m p}\right)$, flow rate $(Q)$, current $(I)$, and piston position $(x)$ for $V_{c}$ changing from 0 to $5 \mathrm{~V}$ with a frequency of $200 \mathrm{~Hz}$ and $\% D C=70 \%\left(I_{\max }=10 \mathrm{~A}\right)$.

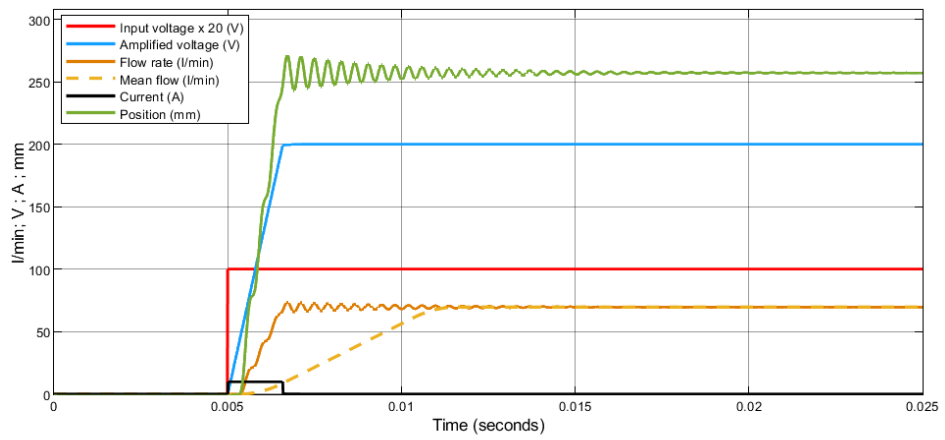

Fig. 9. Numerical predictions of amplified voltage $\left(V_{\text {amp }}\right)$, flow rate $(Q)$, current $(I)$, and piston position $(x)$ for $V_{c}$ changing from 0 to $5 \mathrm{~V}$ with a frequency of $200 \mathrm{~Hz}$ and $\% D C=100 \%\left(I_{\max }=10 \mathrm{~A}\right)$.

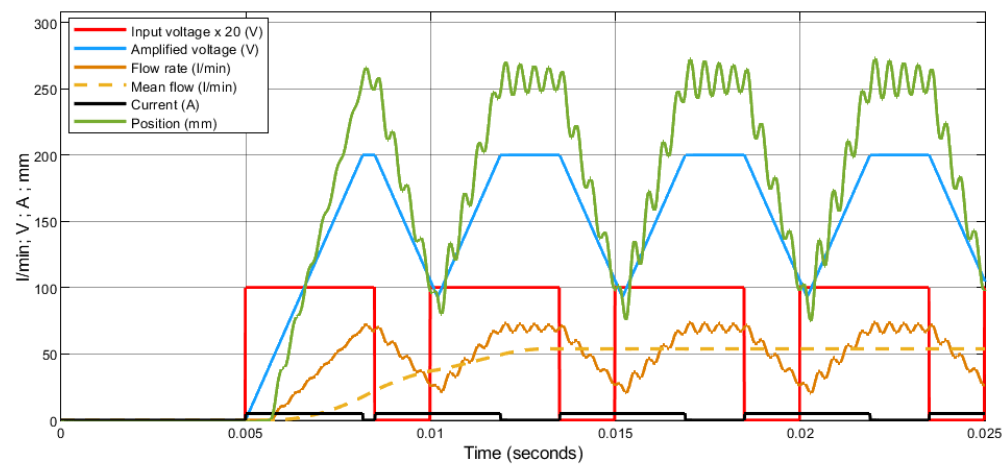

Fig. 10. Numerical predictions of amplified voltage $\left(V_{a m p}\right)$, flow rate $(Q)$, current (I), and piston position $(x)$ for $V_{c}$ changing from 0 to $5 \mathrm{~V}$ with a frequency of $200 \mathrm{~Hz}$ and $\% D C=70 \%\left(I_{\max }=5 \mathrm{~A}\right)$.

Therefore, the peak current must be taken larger; this means that a high current amplifier is needed for this purpose. The peak current occurs only for a short period of time; however, its effects on the heat generated should be investigated properly. 
Apart from this, the previous graphs have shown that the proposed valve architecture is feasible and, by virtue of the low pressure drops, has the advantage of significantly reducing the power losses compared to a spool valve.

\section{Conclusions}

Digital hydraulics is a promising new field with the potential to offer previously unachievable efficiencies. Its success will depend on the development of novel high switching ON/OFF valves. A large unit should switch in less than $5 \mathrm{~ms}$, generating very low pressure drops even for high flow rates (i.e., 10 bar at $60 \mathrm{~L} / \mathrm{min}$ ). In this paper, a feasibility study of a new valve architecture based on the use of a piezo ring stack was performed. The proposed valve is a $2 / 2$ poppet type valve, in which a ring stack directly moves the valve piston inserted through the hole of the stack. Well established equations, implemented in a Simulink model, were used to simulate this valve. In the simulated control system, the input pulse voltage was varied from 0 to $5 \mathrm{~V}$ with a frequency of $200 \mathrm{~Hz}$; by changing the duty cycle of the pulse, it was possible to change the average flow through the valve. The simulations showed that this control strategy is very effective: a maximum flow rate of 70 $1 /$ min was obtained for a pressure drop of 10 bar and $\% D C=100 \%$; the reduction of the duty cycle allowed the average flow rate to be reduced accordingly by keeping the pressure drop set to 10 bar. The main issue of such a control strategy is the high peak current generated, due both to the high capacitance of the ring stack and to the high frequency of the pulse. Simulations were also performed by setting a current limiter in the code to reduce the peak current. It was predicted that limiting the maximum current to $10 \mathrm{~A}$ does not affect the regulation of the valve. However, for a lower current limit, the response of the amplifier worsened, thus affecting the valve regulation, which was very poor in these conditions.

The results of this study can be summarised by listing the disadvantages and advantages of the proposed solution. The disadvantages are the large size of the ring stack (the length of the stack employed is $200 \mathrm{~mm}$ ), the need for a high-performance amplifier, and the high peak current generated. The main advantage is the low pressure drop generated by this architecture and, hence, the much lower power consumption than a spool modulating valve. This study lays down the basis for deeper investigations of the studied architecture, including experimental tests aimed at assessing the effects of hysteresis and peak current generated.

\section{References}

1. P. Tamburrano, A.R. Plummer, E. Distaso, R. Amirante, Int. J. Fluid Power, 20(1), 5398 (2019).

2. P. Tamburrano, A.R. Plummer, E. Distaso, R. Amirante, J. Dyn. Syst. Meas. Control, 141(2), 020801 (2019).

3. P. Tamburrano, A.R. Plummer, P. Elliott, P. De Palma, E. Distaso, R. Amirante, Internal leakage in the main stage of servovalves: an analytical and CFD analysis, in AIP Conference Proceedings, 2191(1), 020146 (2019).

4. P. Tamburrano, A. R. Plummer, P. Elliott, W. Morris, S. Page, E. Distaso, R. Amirante, P. De Palma, 2D CFD analysis of servovalve main stage internal leakage, in Proceedings of the ASME/BATH 2019 Symposium on Fluid Power and Motion Control, October 7-9, Sarasota, FL, USA (2019). 
5. A. Ellman, Leakage behaviour of four-way servovalve, in Proceedings of the ASME Fluid Power Systems and Technology, Vol. 5, pp. 163-167 (1998).

6. B. Eryilmaz, B. H. Wilson, Modeling the internal leakage of hydraulic servovalves, in International Mechanical Engineering Congress and Exposition, ASME, vol. 69, pp. 337-343 (2000).

7. P. Tamburrano, R. Amirante, E. Distaso, A.R. Plummer, A Novel Piezoelectric DoubleFlapper Servovalve Pilot Stage: Operating Principle and Performance Prediction, in Proceedings of the BATH/ASME 2018 Symposium on Fluid Power and Motion, Bath, UK, September 12-14, 2018. V001T01A032. ASME.

8. P. Tamburrano, A.R. Plummer, P. De Palma, E. Distaso, R. Amirante. Energies, 13(9), 2267 (2020).

9. P. Tamburrano, A.R. Plummer, P. De Palma, E. Distaso, R. Amirante. Energies, 13(3), 671 (2020).

10. H. Merritt. Hydraulic Control System. (John Wiley and Sons, Hoboken, NJ, 1967).

11. Q. Zhang, X. Kong, B. Yu, K. Ba, Z. Jin, Y. Kang. Appl. Sci., 10(2), 579 (2020).

12. M. Pan, N. Johnston, A. Plummer, S. Kudzma, A. Hillis. Proc. Inst. Mech. Eng., I: J. Syst. Control Eng., 228(1), 12-25 (2014).

13. M. Pan, N. Johnston, J. Robertson, A. Plummer, A. Hillis, H. Yang, J. Dyn. Syst. Meas. Control, 137(12), 121003 (2015).

14. Valmet Forward. https://www.valmet.com/media/articles/up-and-running/newtechnology/FPDigHydr/. Accessed on 1 April 2021.

15. G. Changbin, J. Zongxia, Proc. Inst. Mech. Eng., Part C, 228(1), 169-185 (2014).

16. Y. B. Bang, K. I. Lee, C. S. Joo, J. W. Hur, Proc. Inst. Mech. Eng., Part C, 218(1), 5365 (2004).

17. M. Reichert, H., Development of high-response piezo servovalves for improved performance of electrohydraulic cylinder drives. $\mathrm{PhD}$ thesis. Aachen university (2010).

18. J. E. Lindler, E. H. Anderson, Smart Structures and Materials 2002: Industrial and Commercial Applications of Smart Structures Technologies, 4698, 488-496 (2002).

19. P. Tamburrano, P. De Palma, A. R. Plummer, E. Distaso, R. Amirante, Feasibility study of using amplified piezo-stack actuators for the actuation of direct drive servovalves, in E3S Web Conf, 197, 07004 (2020).

20. Noliac. Available online: http://www.noliac.com/products/actuators/. Accessed on 1 August 2019.

21. Y. K. Yong, Front. Mech. Eng., 2, 8 (2016).

22. Matlab \& Simulink. SimscapeTM user's guide R2019a. The MathWorks, Inc. (2019).

23. J. D. Stringer. Hydraulic Systems Analysis: An Introduction (Macmillan Publishers Limited, Palgrave, London, 1976).

24. L. J. Persson, A.R. Plummer, C.R. Bowen, I. Brooks. Design and Modelling of a Novel Servovalve Actuated by a Piezoelectric Ring Bender. In Proceedings of the ASME/BATH 2015 Symposium on Fluid Power and Motion Control, October 12-14, 2015, Chicago, Illinois, USA, (2015).

25. L. Xu, H. Li, P. Li, C. Ge. Sensors, 20(22), 6528 (2020).

26. PI Ceramic documentation. https://www.pi-usa.us/en/products/piezo-motors-stagesactuators/piezo-motion-control-tutorial/tutorial-4-38. Accessed on 1 July 2021.

27. F. W. Zeng, H. Wang, H. T. Lin, J. Appl. Phys., 114(2), 024101 (2013). 